\title{
Avaliação integrada do impacto do uso de agrotóxicos sobre a saúde humana em uma comunidade agrícola de Nova Friburgo, RJ
}

\author{
Integrated evaluation of the health impact of \\ pesticide use in a community at Nova Friburgo, RJ
}

Josino C. Moreira 1, Silvana C. Jacob 1

Frederico Peres 1, Jaime S. Lima 2

Armando Meyer 1, Jefferson J. Oliveira-Silva 1,2,5

Paula N. Sarcinelli 1, Darcilio F. Batista 1

M ariana Egler 1, M auro V. Castro Faria 3

Alberto José de Araújo 4, Alexandre H. Kubota 1

M ônica de O. Soares 2, Sergio R. Alves 1

Cláudia M. M oura 4, Rosane Curi 1

\footnotetext{
1 Centro de Estudos da Saúde do Trabalhador e Ecologia Humana, Escola Nacional de Saúde Pública, Fundação Oswaldo Cruz. Av. Brasil 4365 , Manguinhos, 21041-210, Rio de Janeiro RJ. josinocm@ensp.fiocruz.br

2 Departamento de Ciências Fisiológicas, Instituto Biomédico, Universidade do Rio de Janeiro.

3 Hospital Clementino

Fraga Filho, Programa de Medicina O cupacional, Universidade Federal do Rio de Janeiro.

4 Departamento de Biologia Celular e Genética, Instituto de Biologia Roberto Alcântara Gomes, Universidade do Estado do Rio de Janeiro.

5 Faculdade de Ciências

Farmacêuticas,

Universidade de São Paulo.
}

Resumo 0 impacto do uso de agrotóxicos sobre a saúde humana é um problema que tem merecido atenção da comunidade científica em todo o mundo, sobretudo nos países em desenvolvimento. 0 consumo de agrotóxicos na regi ão sudeste do Brasil está estimado em $12 \mathrm{~kg}$ de agrotóxico/trabalhador/ano. Em algumas áreas agrícolas do Estado do Rio de Janeiro, como na região da M icrobacia do Córrego de São Lourenço, N ova Friburgo, o consumo de agrotóxico foi estimado em $56 \mathrm{~kg}$ de agrotóxico/trabalhador/ano. Elevados níveis de contaminação humana e ambiental foram encontrados nesta região, como decorrência do uso extensivo destes agentes químicos. A avaliação do impacto sobre a saúde humana implica o conhecimento e a visualização da importância/magnitude relativa de cada uma das vias de contaminação. Inúmeros fatores, que, em geral, encontram-se inter-relacionados, contribuem para a situação encontrada na M icrobacia do Córrego de São Lourenço e a forma mais adequada de se avaliar toda a dimensão deste problema é o uso de uma abordagem integrada.

Palavras-chave Contaminação humana eambiental por Agrotóxicos, Avaliação de riscos, Saúde do trabalhador 


\section{Introdução}

Desde a década de 1950, quando se iniciou a "revolução verde", foram observadas profundas mudanças no processo tradicional de trabalho na agricultura bem como em seus impactos sobre o ambiente ea saúde humana. Novas tecnologias, muitas delas baseadas no uso extensivo de agentes químicos, foram disponibilizadas para o controle de doenças, aumento da produtividade e proteção contra insetos e outras pragas. Entretanto, essas novas facilidades não foram acompanhadas pela implementação de programas de qualificação da força de trabaIho, sobretudo nos países em desenvolvimento, expondo as comunidades rurais a um conjunto de riscos ainda desconhecidos, originado pelo uso extensivo de um grande número de substâncias químicas perigosas e agravado por uma série de determinantes de ordem social.

No Brasil, problemas sociais como a urbanização acelerada e desorganizada verificada desde 1970 trouxeram importante contribuição para a situação ora vigente no ambiente rural brasileiro, geralmente caracterizado pela falta de saneamento básico, suprimento de água potável, transporte, etc. De 1970 a 1996, o percentual de brasileiros residentes em áreas rurais diminui de 45 para $12 \%$. Em al guns estados como Rio deJaneiro e São Paulo, tal situação é ainda mais grave: cerca de $90 \%$ da população vive em áreas urbanas (M M A, 1996).

0 governo brasileiro tem, consistentemente, dado muito pouca atenção a esses problemas, optando por concentrar esforços na solução de problemas de ordem política e/ou econômica. Ao mesmo tempo, incentiva continuamente 0 aumento da produção agrícola, uma vez que a exportação de produtos agropecuários é responsável por $39 \%$ da balança comercial brasileira (M M A, 1996).

Esses fatores fizeram com que um grupo cada vez menor de agricultores, na sua maioria despreparados e não-assistidos, fosse responsável por uma produtividade cada vez mais elevada, conseguida, na grande maioria das vezes, com a utilização crescente de agrotóxicos e fertilizantes.

Atualmente estima-se que cerca de 2,5 a 3 milhões de toneladas de agrotóxicos são utilizados a cada ano na agricultura, envolvendo um comércio de cerca de 20 bilhões de dólares (Agrofit, 1998). No Brasil, o consumo desses produtos encontra-se em franca expansão. 0 país é responsável pelo consumo de cerca de
$50 \%$ da quantidade de agrotóxicos utilizados na América Latina, o que envolve um comércio estimado em cerca de US\$2.56 bilhões em 1998 (Sindag, 1999). Atualmente o Brasil ocupa o quarto lugar no ranking dos países consumidores de agrotóxicos.

0 consumo de agrotóxicos na região sudeste do Brasil está estimado em 12kg de agrotóxico/ trabalhador/ano podendo atingir valores bem superiores a este em algumas áreas produtivas.

A ampla utilização desses produtos, o desconhecimento dos riscos associados a sua utilização, o conseqüente desrespeito às normas básicas de segurança, a livre comercialização, a grande pressão comercial por parte das empresas distribuidoras e produtoras e os problemas sociais encontrados no meio rural constituem importantes causas que levam ao agravamento dos quadros de contaminação humana e ambiental observados no Brasil. A esses fatores podem ser acrescentados a deficiência da assistência técnica ao homem do campo, a dificuldade de fiscalização do cumprimento das leis e a culpabilização dos trabal hadores como contribuintes para a consolidação do impacto sobre a saúde humana, decorrente da utilização de agrotóxicos, como um dos maiores problemas de saúde pública no meio rural, principalmente nos países em desenvolvimento (Pimentel, 1996; Peres, 1999; O liveira-Silva et al., 2000).

A magnitude do impacto resultante do uso de agrotóxicos sobre o homem do campo, no Brasil, pode ser depreendida a partir dos dados do M inistério da Saúde. De acordo com estes dados, em 1996 houve 8.904 casos de intoxicações por agrotóxicos, dos quais 1.892 (21,25\%) foram observados no meio rural (Sinitox, 1998). Estes dados, entretanto, não refletem a real dimensão do problema uma vez que os mesmos advêm de Centros de Controle de Intoxicações, situados em centros urbanos, inexistentes em várias regiões produtoras importantes ou de difícil acesso para muitas populações rurais.

Alguns trabalhos realizados para avaliar os níveis de contaminação ocupacional por agrotóxicos em áreas rurais brasileiras têm mostrado níveis de contaminação humana que variam de 3 a 23\% (Almeida \& Garcia, 1991; Faria et al., 2000; Gonzaga et al., 1992). Considerando-se que o número de trabal hadores envolvidos com a atividade agropecuária no Brasil, em 1996, era estimado em cerca de 18 milhões e aplicando-se o menor percentual de contaminação relatado nesses trabal hos (3\%), o número de indivíduos contaminados por agrotóxicos no Brasil 
deve ser de aproximadamente 540.000 com cerca de 4.000 mortes por ano. Além disso, estes dados não consideram o impacto indireto resultante da utilização de tais produtos.

É importante real çar que, com exceção de al guns grandes exportadores, a agricultura próxima dos grandes centros é de pequeno porte e uma atividade eminentemente familiar, em que adultos e crianças se ajudam mutuamente no trabal ho. Isto faz com que as crianças e os jovens também estejam sujeitos a elevado risco de contaminação. Esse problema é ainda mais preocupante uma vez que pouco se sabe da ação de uma exposição continuada a compostos sobre o corpo humano ainda em desenvolvimento e que várias substâncias utilizadas como agrotóxicos são suspeitas de apresentarem atividade carcinogênica ou hormonal.

M esmo assim, a grande maioria dos estudos realizados no Brasil aborda contaminações diferenciadas, ou seja, humana (ocupacional, acidental ou suicida) e ambiental, isoladamente, não considerando a natureza holística, a multiplicidade de rotas e a grande variabilidade das causas do problema, cuja acuidade de compreensão exige uma avaliação integrada.

Este trabal ho discute os resultados obtidos em um programa de pesquisa/intervenção integrado sobre o destino dos agrotóxicos na região da Microbacia do Córrego de São Lourenço, M unicípio de Nova Friburgo, RJ, e mostra a necessidade de um enfoque integrado/à luz de diversas disciplinas para a avaliação e controle dos vários fatores que contribuem para 0 impacto da contaminação por agrotóxicos no meio rural brasileiro.

\section{C aracterísticas geográficas e socioeconômicas do local de estudo}

A localidade de São Lourenço está situada a $45 \mathrm{~km}$ a sudoeste da sede do município de Nova Friburgo, na divisa deste município com o de Teresópolis, e conta com uma população aproximada de 600 habitantes. Localiza-se em um vale a $1.000 / 1.200 \mathrm{~m}$ de altitude, cercado por montanhas que atingem $2.200 \mathrm{~m}$ e cortado pelo Córrego de São Lourenço e seus afluentes (Figura 1). Quatro outras pequenas localidades se situam nesta mesma região, que se caracteriza por ser a principal produtora de olerícolas do Estado do Rio de Janeiro.

A estrutura fundiária está baseada em pequenas propriedades rurais, onde a mão-de- obra é exclusivamente familiar. A maioria dos trabalhadores rurais (produtores) possui o curso primário como grau de escolaridade, sendo que $32 \%$ não haviam freqüentado escola (analfabetos e alfabetizados em casa por pai e/ou mãe). Sabendo-se que o ensino rural no Brasil apresenta sérias deficiências de qualidade, pode-se depreender que aqueles que não completaram o curso primário, por abandono, possuem elementos mínimos de leitura e de compreensão de textos, fatos estes comprovados pelas observações de campo. De fato, cerca de $58 \%$ da população local (analfabetos, alfabetizados em casa e aqueles com curso primário incompleto) têm nenhuma ou mínima habilidade de leitura/escrita, configurando um perfil de escolaridade baixo como observado no homem do campo, em níveis regional e nacional (Peres, 1999).

Na região da M icrobacia do Córrego de São Lourenço, o consumo de agrotóxico foi estimado em 56,5kg de agrotóxico/trabalhador/ano. Esse elevado consumo, associado a outras características comuns às áreas rurais brasileiras, amplifica o impacto dessas substâncias químicas sobre o homem eo ambiente.

\section{0 objeto complexo do impacto dos agrotóxicos sobre a saúde}

Além da seriedade com que vários casos de contaminação humana e ambiental têm sido identificados no meio rural, moradores de áreas próximas e, eventualmente, os do meio urbano também se encontram sob risco, devido à contaminação ambiental e dos alimentos. No que tange ao impacto sobre saúde humana causado por agrotóxicos, diversos fatores podem contribuir. A figura 2 sintetiza al guns dos principais fatores através dos quais o impacto da contaminação por agrotóxicos é estabelecido, assim como identifica alguns dos determinantes (de ordem cultural, social e econômica) que podem vir a minimizar ou amplificar este impacto.

Como pode ser observado, a saúde humana pode ser afetada pelos agrotóxicos diretamente, por meio do contato direto do organismo com estas substâncias, ou ainda indiretamente, por intermédio do desenvolvimento de algum fator impactante como resultado do uso desses agentes químicos.

Três vias principais são responsáveis pelo impacto direto da contaminação humana por agrotóxicos. 
Figura 1

Localização geográfica da região da microbacia do Córrego de São Lourenço,

Nova Friburgo, RJ.
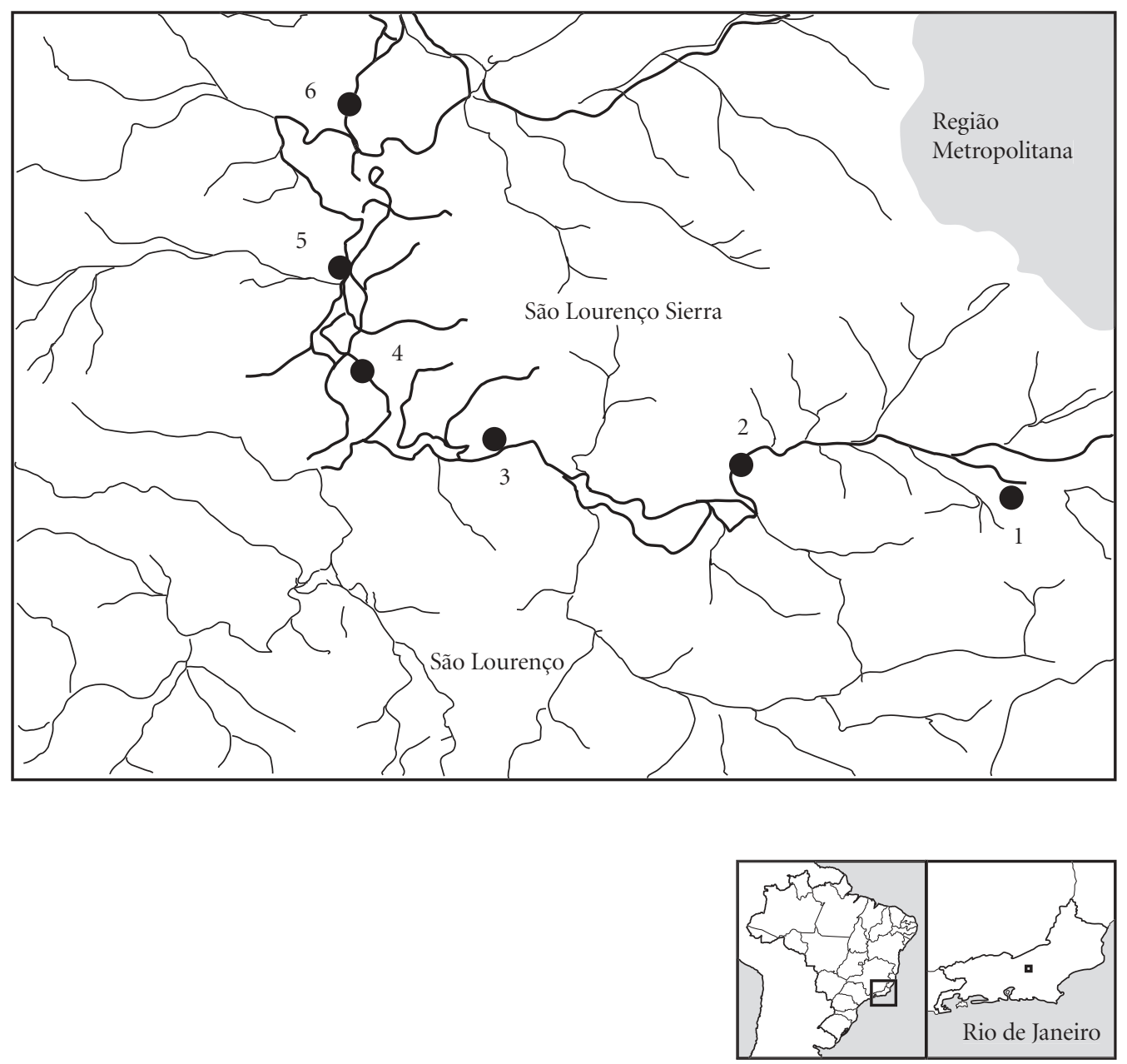

A via ocupacional, que se caracteriza pela contaminação dos trabalhadores que manipulam essas substâncias. Esta contaminação é observada tanto no processo de formulação (mistura e/ou diluição dos agrotóxicos para uso), quanto no processo de utilização (pulverização, auxílio na condução das mangueiras dos pulverizadores - a "puxada" - descarte de resíduos e embalagens contaminadas, etc.) e na colheita (onde os trabalhadores manipulam/entram em contato com o produto contaminado). Embora atinja uma parcela mais reduzida da população (os trabal hadores - rurais ou guardas de ende- mias, por exemplo - que manipulam estes produtos em seu processo de trabalho), esta via é responsável por mais de $80 \%$ dos casos de intoxicação por agrotóxicos, dada à intensidade e à freqüência com que o contato entre este grupo populacional e o produto é observado.

A via ambiental, por sua vez, caracteriza-se pela dispersão/distribuição dos agrotóxicos ao longo dos diversos componentes do meio ambiente: a contaminação das águas, através da migração de resíduos de agrotóxicos para lençóis freáticos, leitos de rios, córregos, lagos e lagunas próximos; a contaminação atmosférica, resul- 


\section{Figura 2}

Representação esquemática das princi pais vias responsáveis pelo impacto da contaminação humana por agrotóxicos

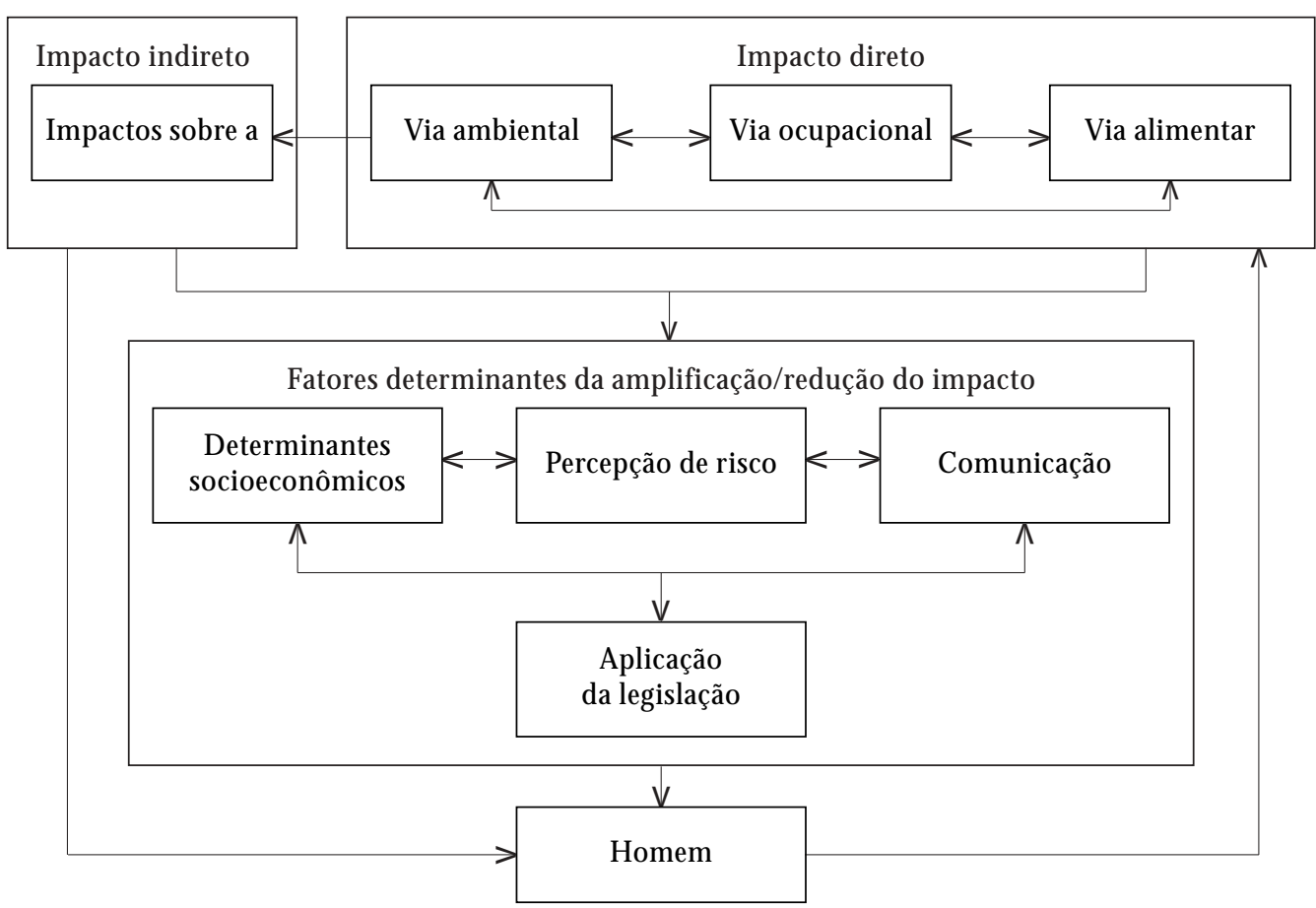

tante da dispersão de partículas durante o processo de pulverização ou de manipulação de produtos finamente granulados (durante o processo de formulação) e evaporação de produtos mal-estocados; e a contaminação dos solos. A contribuição da via ambiental é de fundamental importância para o entendimento da contaminação humana por agrotóxicos. Acredita-se que um maior número de pessoas estejam expostas através desta via, em relação à via ocupacional; entretanto, o impacto resultante da contaminação ambiental é, em geral, consideravelmente menor que 0 impacto resultante da via ocupacional.

E a via alimentar caracteriza-se pela contaminação relacionada à ingestão de produtos contaminados por agrotóxicos. 0 impacto sobre a saúde provocado por esta via é, comparativamente, menor, devido a diversas razões, tais como: a concentração dos resíduos que permanece nos produtos; a possibilidade de eliminação dos agrotóxicos por processos de beneficia- mento do produto (cozimento, fritura, etc.); 0 respeito ao período decarência, etc. Esta via atinge uma parcela ampla da população urbana, os consumidores.

A saúde das comunidades pode ser também afetada pelo uso de agrotóxicos através de mecanismos indiretos. Um exemplo desta possibilidadeéo impacto da contaminação sobre a biota local e de áreas próximas. Ou seja, a utilização desses agentes pode favorecer a colonização da área por espécies mais resistentes, substituindo espécies inofensivas por outras mais perigosas para o homem (vetores, etc.). Outros exemplos do impacto indireto são os efeitos sobre comunidades de crustáceos e peixes, habitantes de ambientes limnológicos próximos, diminuindo a biodiversidade e gerando, assim, diversos efeitos sobre o equilíbrio ecológico local.

Diversos fatores - de ordem social, cultural e econômica - apresentam-se como determinantes da amplificação ou da redução da contaminação humana. Embora consideremos que 
o sujeito não possa ser entendido apenas como o indivíduo susceptível/sensível às injúrias de correntes do uso de agrotóxicos, neste trabalho serão abordados apenas três fatores considerados de grande importância para a visualização da situação de risco no meio rural: o processo de comunicação; a percep ção de risco; e os de terminantes socioeconômicos.

0 termo comunicação tem origem no Latim: communicare, que significa "pôr em comum" (Penteado, 1964). A comunicação, como um processo social, está associada à idéia de interação; é, portanto, um processo dinâmico. Podemos considerar que existem padrões diferenciados de comunicação dentro de uma mesma sociedade, ou grupo organizado. Podemos considerar claramente um padrão de comunicação "rural", em comparação a um padrão "urbano" que, segundo Bordenave (1988), se relaciona com o fato de a população rural concentrar suas atividades e seu comportamento ao redor de uma atividade toda especial, complexa e marcante que é a agricultura. As comunidades resultantes da ocupação agrícola e do hábitat rural pensam, sentem eagem de maneira diferente da dos habitantes das cidades, comunicando-se também através de códigos e mei os próprios.

Tal diferenciação relaciona-se não somente com o isolamento do meio rural, devido às distâncias entre os sítios/lavouras e vilarejos e núcleos e a dificuldade/ precariedade dos transportes, mas também por características próprias do processo de produção rural, como a jornada exaustiva e o trabalho que demanda esforços físicos fatigantes, restringindo o tempo livre disponível para as atividades sociais e comunitárias (Peres, 1999). 0 analfabetismo socialmente determinado e o precário acesso às informações e à educação formal, nas comunidades em questão, também contribuem para uma diferenciação dos padrões de comunicação. A comunicação sobre agrotóxicos é, portanto, um determinante fundamental da contaminação humana por estas substâncias, razão pela qual a análise do processo de comunicação deve, obrigatoriamente, fazer parte dos estudos de avaliação integrada da contaminação por agrotóxicos.

A adoção de novas tecnologias, ou empreendimentos tecnológicos de grandes proporções, sempre esteve associada ao impacto que tais eventos venham a ter em uma sociedade, ou grupos sociais envolvidos (Wiedermann, 1993). Entretanto, as análises técnicas de riscos tendem a subestimar (ou ignorar) a dimensão social, a qual inevitavelmente é parte dos próprios riscos e suas análises. Os riscos tecnológicos/ambientais, mais do que entidades físicas que existiriam independentemente dos seres humanos que os analisam e vivenciam, são processos de construção social. Nesse contexto, os estudos de percepção de risco aparecem como uma nova área de investigação dentro do campo da análise de riscos, baseada nas crenças, visões, sensações e interpretações da população/grupo populacional/indivíduo relacionado com o risco.

Segundo Wiedermann (1993), a percepção de risco é baseada principalmente em imagens e crenças. Em uma menor extensão, a percepção de risco tem raízes na experiência anterior como, por exemplo, acidentes que um motorista já teve, o conhecimento de desastres anteriores e a relação com informações ou facilidade sobre a probabilidade de um avião cair. Deve-se levar em conta que a percepção de risco é baseada em diferentes "backgrounds" de conhecimento. Ainda segundo o autor, a percepção de risco é definida como sendo a habilidade de interpretar uma situação de potencial dano à saúde ou à vida da pessoa, ou de terceiros, baseada em experiências anteriores e sua extrapolação para um momento futuro. Esta habilidade varia de uma vaga opinião a uma firme convicção.

De uma maneira geral, podemos conceber que uma grande parcela da população está exposta aos efeitos nocivos de produtos agrotóxicos. A contaminação (ou não) dessas pessoas, muito provavelmente, está relacionada não apenas ao grupo ao qual pertencem, mas também à maneira como, individual ou coletivamente, essas pessoas concebem e se posicionam frente ao risco a que estão expostas. Conhecer a percepção deste risco, por parte dos grupos populacionais ou profissionais a ele expostos é, portanto, fundamental para a construção de estratégias de intervenção sobre o problema.

Diversos determinantes socioeconômicos estão relacionados com a amplificação e a redução do impacto da contaminação humana por agrotóxicos, dentre os quais podemos destacar: o nível educacional (Oliveira-Silva, 2000); a habilidade de leitura/escrita (Peres, 1999); a renda familiar, etc. 0 conheci mento e o mapeamento destes determinantes é de fundamental importância para uma análise mais acurada do impacto da contaminação humana por agrotóxicos. 


\section{Metodologia}

Este estudo envolveu o levantamento de fatores socioeconômicos, educacionais e comunicacionais, assim como a análise da contaminação ambiental e humana causada por agrotóxicos utilizados na M icrobacia do Córrego de São Lourenço, Nova Friburgo, RJ.

O levantamento dos dados relacionados aos fatores socioeconômicos foi realizado em dois momentos principais: durante entrevistas semi-estruturadas, baseadas em metodologia de pesquisa social (de caráter qualitativo) e durante as entrevistas real izadas previamente à coleta de sangue, para determinação dos níveis de contaminação dos trabalhadores.

Para a análise do processo de comunicação rural na região (Peres, 1999), inicialmente, foram realizadas entrevistas semi-estruturadas, contendo questões relativas ao regime de uso de agrotóxicos e ao histórico da implementação desta tecnologia naquela localidade. Posteriormente, foi realizada uma avaliação da recepção das informações disponíveis sobre estes produtos (rótulos e bulas de produtos, cartilhas, folders e outros materiais informativos). N essa segunda etapa, trechos escritos ou figuras previamente selecionadas, dentre o material utilizado para informação sobre os agrotóxicos, eram apresentados aos trabal hadores, solicitando-se que eles os interpretassem e relatassem o seu entendimento.

A avaliação dos trabal hadores adultos ocupacional mente expostos envolveu uma população de 101 trabalhadores e foi realizada através de 3 instrumentos:

1) Investigação epidemiológica, feita com a aplicação de questionários especificamente elaborados para tal;

2) Investigação clínica, por meio de dois tipos de instrumentos: o questionário médico paralelo à consulta médica, que focalizou os dados sociais e a história de patologias anteriores; e o exame físico;

3) Monitoramento biológico, realizado através de exames laboratoriais tais como hemograma e perfil bioquímico, analisando-se indicadores hepáticos, renais, perfil protéico e de células sangüíneas para compor um quadro clínico-laboratorial que auxiliasse na análise de contaminação dos trabalhadores por agrotóxicos, e que pudesse também indicar possíveis outros fatores de confundimento na caracterização da doença ocupacional, tais como desnutrição e doença hepática.
Nessa etapa também foram utilizados indicadores biológicos de exposição específicos (butirilcolinesterase plasmática e acetilcolinesterase eritrocitária). Essas últimas análises foram realizadas pelo método de Ellman modificado (Cunha, 1996 e O liveira-Silva, 2000).

No estudo da contaminação de crianças e adolescentes foram avaliados 76 indivíduos. A maior parte dos participantes era estudante de uma das cinco escolas (quatro de ensino do tipo tradicional brasileiro - estudo por quatro horas/ dia - e um de alternância, onde os alunos têm atividades semanais alternadas: ensino e trabaIho na lavoura) existentes na região estudada e também alguns não-estudantes. Neste segmento foram realizadas as etapas de investigação epidemiológica e de monitoramento clínico dos indicadores colinesterásicos, por meio do kit EQM, da EQM Research (Cincinatti, Ohio, USA).

Como as crianças residentes na Vila de São Lourenço eram poucas para se constituírem um grupo significativo, este estudo envolveu também crianças de outras quatro vilas vizinhas, situadas na mesma região estudada.

A determinação da concentração dos agrotóxicos inibidores das colinesterases em amostras de água do rio São Lourenço foi realizada através da metodologia baseada na ini bição da acetilcolinesterase isolada de cérebro de ratos (Cunha Bastos et al., 1991 e Lima et al., 1996). Essas amostras foram coletadas mensal mente entre os anos de 1998 e 1999. Além deste parâmetro, foram ainda determinados al guns outros parâmetros físico-químicos da água do rio São Lourenço ( $p H$ e dureza).

Avaliou-se ainda o efeito da utilização de agrotóxicos sobre a biota aquática (macroinvertebrados). A coleta biológica foi realizada através de amostradores do tipo Surber em hábitats de riffle e pool (M errit \& Cummins, 1996).

Amostras de vegetais foram coletadas nas cooperativas de distribuição e analisadas, utilizando-se a mesma metodologia utilizada nas análises de água.

\section{Resultados}

Como ponto inicial deste trabalho, foi realizada a avaliação das características socioeconômicas e culturais da população em estudo. Algumas características importantes observadas nos grupos humanos (adultos e crianças) estudados são apresentadas na tabela 1. 
Tabela 1

Algumas características dos grupos estudados

\begin{tabular}{|c|c|c|}
\hline Característica & Adultos & Crianças \\
\hline Idade (média) & 34.9 anos $(p=10,26)$ & $13.6 \operatorname{anos}(p=2.37)$ \\
\hline Sexo $(\%)$ & $\begin{array}{l}85.2 \text { (homens) } \\
14.8 \text { (mulheres) }\end{array}$ & $\begin{array}{l}69.7 \text { (homens) } \\
30.3 \text { (mulheres) }\end{array}$ \\
\hline Nível educacional (\%) & $\begin{array}{l}<4 \text { anos de estudo }-32.1 \\
4 \text { - } 8 \text { anos de estudo }-64.9 \\
>8 \text { anos de estudo }-3\end{array}$ & $\begin{array}{l}<4 \text { anos de estudo - } 19.8 \\
4 \text { - } 8 \text { anos de estudo - } 76.1 \\
>8 \text { anos de estudo - } 3.1\end{array}$ \\
\hline $\begin{array}{l}\text { Uso de equipamento } \\
\text { individual de proteção (\%) }\end{array}$ & 37.7 (sim); 62.3 (não) & 61.4 (sim); 38.6 (não) \\
\hline $\begin{array}{l}\text { Máscaras } \\
\text { Vestimentas (luvas, etc.) }\end{array}$ & $\begin{array}{l}8(f) ; 3(a v) ; 89(n) \\
5(f) ; 2(a v) ; 93(n)\end{array}$ & $\begin{array}{l}13(f) ; 5(a v) ; 82(n) \\
8(f) ; 3(a v) ; 89(n)\end{array}$ \\
\hline $\begin{array}{l}\text { Atividades (\% envolvido) } \\
\text { Preparação } \\
\text { Aplicação } \\
\text { Cultivo } \\
\text { Transporte }\end{array}$ & $\begin{array}{l}82.3 \\
88.9 \\
96.5 \\
62.3\end{array}$ & $\begin{array}{l}33.3 \\
75.8 \\
75.5 \\
22.4\end{array}$ \\
\hline $\begin{array}{l}\text { Contato do agrotóxico } \\
\text { com a pele }(\%)\end{array}$ & 98.6 & 78.0 \\
\hline $\begin{array}{l}\text { Recebeu algum tipo de treinamento } \\
\text { para manipular agrotóxicos }(\%)\end{array}$ & 47.8 & 52.0 \\
\hline $\begin{array}{l}\text { Relatou algum sintoma observado } \\
\text { após o processo de aplicação (\%) }\end{array}$ & 47.8 & 34.0 \\
\hline
\end{tabular}

$\mathrm{f}$ = freqüentemente; av = às vezes; e $\mathrm{n}$ = nunca

Estes dados mostram que o trabalho rural é realizado majoritariamente por homens, com um envolvimento significativo de crianças e de jovens. No segmento relativo às crianças trabalhadoras, a partici pação de jovens do sexo feminino é importante. A priori, verifica-se que o nível de escolaridade está melhorando, bem como alguns cuidados básicos para proteção individual. Por outro lado fica patente a falta de treinamento e de orientação para lidar com estas substâncias.

A comunidade estudada utiliza em seu trabaIho mais de 100 diferentes formulações de agrotóxicos. M etamidophos (uso relatado por $93,8 \%$ dos trabalhadores entrevistados), esfenvalerate (68.8\%), mancozeb $(62.5 \%)$, paraquat (62.5\%) e deltametrina (35\%) são os agrotóxicos mais utilizados, ge ralmente sem nenhuma orientação técnica.

A análise do processo de comunicação e da re cepção das informações sobre os agrotóxicos nesta região apontou para uma série de desafios, a serem superados em áreas rurais (Peres, 1999). Dentre estes, pode-se destacar o teor altamente técnico das informações prestadas, como pode ser observado nos dizeres constantes no rótulo de Gramoxone ${ }^{\circledR}$ (paraquat, um dos produtos mais utilizados na região e no país): Esta formulação contém um agente emético, portanto não controle vômito em pacientes recém-intoxicados por via oral, até que pela ação do esvaziamento gástrico do herbicida, o líquido estomacal venha a ser claro.

Nenhum dos trabal hadores entrevistados conseguiu entender o sentido dessa orientação, de extrema importância no caso de uma contaminação (acidental ou não) por via oral (este produto apresenta a coloração dos refrigerantes tipo cola - amarronzada - fato que é responsável pela maioria dos casos de ingestão acidental por via oral, sobretudo entre crianças).

Diante da explicação sobre o significado da frase, um trabalhador sugeriu: Em vez disso aí, o sujeito não podia escrever "se o caboclo beber 0 veneno, deixe ele vomitar atéas tripa!" (Agricultor, 35 anos).

Outro ponto observado durante o estudo da comunicação rural foi a dificuldade de interpretação de figuras presentes em rótulos e 
bulas de formulações de agrotóxicos. N enhum dos entrevistados conseguiu interpretar a totalidade das mensagens contidas em figuras de rótulos e bulas de produtos agrotóxicos, como alguns pictogramas (pequenas figuras com a representação de atividades e/ou equipamentos de proteção indicados - como a "caveirinha", que representa risco de vida/perigo - usados para informar visualmente aos trabal hadores que não possuem habilidade de leitura/escrita sobre os riscos envolvidos com a utilização de tais produtos) e representações gráficas de procedimentos de uso e descarte.

Desta forma, o processo de comunicação rural ainda prevalente no Brasil acaba por contribuir para um agravamento da contaminação humana do trabalhador rural, processo que é coroado por práticas exploratórias de venda associado a um negligenciamento de informações por parte de técnicos do próprio governo e daqueles ligados ao comércio/indústria, que, em última análise, são os responsáveis pelas informações recebidas por 70\% dos trabalhadores entrevistados (Peres, 1999).

\section{A contaminação ambiental}

A utilização maciça de agrotóxicos tem como conseqüência a contaminação de todos os segmentos ambientais. Para avaliar os níveis de contaminação, amostras de água do rio São Lourenço foram coletadas mensalmente em seis pontos ao longo da área em estudo, como mostrado na figura 1.

A análise dessas amostras revelou níveis significativos de agrotóxicos anticolinesterásicos em amostras de água coletadas nos pontos 5 $(76.80 \pm 10.89 \mu \mathrm{g} / \mathrm{L})$ e $6(37.16 \pm 6.39 \mu \mathrm{g} / \mathrm{L})$ no mês de agosto/98 e no ponto 4 (31,37 \pm 1.60 $\mu \mathrm{g} / \mathrm{L}$ ) em abril/99 (Alves, 2000). A constatação da contaminação do ponto 4 sem que fossem observadas contaminações nos pontos situados a jusante (pontos 5 e 6) sugere um processo de contaminação pontual recente e que a conseqüente diluição fez com que as concentrações subseqüentes ficassem abaixo do limite de detecção da metodologia utilizada (estimado em $20 \mu \mathrm{g} / \mathrm{L}$ de equivalentes de metil-paration). Esses valores são muito superiores àqueles recomendados pela legislação brasileira para águas de abastecimento doméstico e utilizadas para irrigação de hortaliças e de plantas frutíferas ( organ ofosforados totais e carbamatos: $10 \mu \mathrm{g} /$ L) (Conama, 1986). Todos os valores elevados foram observados em períodos de prolongada estiagem o que pode ter contribuído para os níveis de concentração encontrados.

Convém realçar que a população da comunidade estudada não dispõe de sistemas de distribuição de água nem de esgoto. A água utilizada nas residências é coletada em minas que nascem nas proximidades ou diretamente no rio São Lourenço.

Embora a metodologia utilizada não tenha evidenciado uma contaminação contínua por agentes anticolinestrásicos, fica evidente que, em algumas oportunidades, os níveis de contaminação são elevados e podem ter impacto significativo sobrea biota.

\section{Impacto sobre a biota}

Com relação às medidas biológicas, foi observada uma redução da riqueza de táxons entre o ponto referência (ponto 1) que apresentou 43 unidades taxonômicas (UTOs) e o ponto mais impactado (ponto 5), onde foram observadas apenas 20 UTOs. Os organofosforados não possuem grande estabilidade e provavelmente se sedimentam pouco. Dessa maneira, os organismos associados ao compartimento coluna d'água são os afetados mais diretamente (táxons de hábitos natatórios e aqueles que vivem fixados a pedras). Em geral, tais organismos são coletores ativos, passivos ou raspadores-herbívoros, alimentando-se principalmente de material orgânico em suspensão ou de detritos e perifíton. O bservou-se que, nesta região, os indivíduos das ordens Ephemeroptera e Plecoptera foram os mais afetados, pois, além de apresentarem tais hábitos, são organismos reconhecidamente sensíveis. $\mathrm{Na}$ área de referência foram encontrados oito gêneros de Ephemeroptera e dois de Plecoptera, enquanto na área degradada apenas um gênero de Ephemeroptera (Baetis, Baetidae).

Os grupos menos afetados foram Chironomidae (Diptera), Simuliidae (Diptera) e Elmidae (Coleoptera). Embora os dois primeiros grupos sejam coletores, ambos são reconhecidamente espécies resistentes à poluição. Os coleopteras raspadores apresentaram uma redução pouco significativa em relação à área referência, pois são favorecidos pelo aumento na abundância de macrófitas aquáticas em decorrência do uso de fertilizantes nas lavouras vizinhas.

A mudança na composição das famílias da ordem Ephemeroptera, com o desaparecimento 
de Leptophlebiidae e sobrevivência de organismos da família Baetidae, indica que a primeira pode ter uma menor tolerância, servindo como um bom bioindicador. Testes ecotoxicológicos estão sendo realizados em laboratório, a fim de avaliar se Leptophlebiidae é menos suscetível do que Baetidae. A princípio os gêneros em estudo são Askola ou Hylister (Leptophlebiidae), e Baetis (Baetidae). Todos estes, cosmopolitas e amplamente distribuídos, ocorreram em grande número nas amostras coletadas. Além disso, estão sendo realizados experimentos de meso-cosmo em riachos de primeira ordem, visando avaliar os efeitos diretos da aplicação de agrotóxicos sobre o restante das comunidades biológicas.

Com isto procura-se estabelecer um índice biológico aplicado a áreas contaminadas por agrotóxicos organofosforados, determinando grupos sensíveis e resistentes e, possivelmente, escores de tolerância. Este índice permitirá avaliar qualitativamente outras regiões impactadas pelo uso deorganofosforados, avaliando a extensão dos danos sobre o meio ambiente aquático.

É importante ressaltar que o rio São Lourenço, poucos quilômetros abaixo da região estudada, recebe outros riachos provenientes de regiões igualmente agrícolas, dando origem ao rio Grande, que é a fonte de água potável para a cidade de Nova Friburgo, importante centro industrial com cerca de 250.000 habitantes.

Análises preliminares de vegetais (tomate, vagem e pimentão) adquiridos no mercado mostraram elevada percentagem (33\% em tomate, $40 \%$ da vagem e $20 \%$ do pimentão) de contaminação por resíduos de agentes anticolinesterásicos. Valores de inibidores da acetilcolinesterase equivalentes a $0.56 \mathrm{mg} / \mathrm{kg}$ de methamidophos foram detectados nestes produtos. Embora a interpretação destes resultados à luz da legi slação brasileira para alimentos seja difícil, uma vez que as quantidades permitidas dependem da substância utilizada, estes certamente demonstram a existência de resíduos indesejáveis nos produtos analisados.

\section{Contaminação humana}

Uma outra avaliação importante deste estudo foi a análise laboratorial das atividades de acetilcolinesterase de membrana de hemácias e butirilcolinesterase plasmática. Os resultados apresentados a seguir se relacionam apenas à contaminação por agrotóxicos inibidores das acetilcolinesterases (organofosforados e carbamatos).
A escolha destes agrotóxicos como ponto de partida para este estudo se deve à elevada utilização destes na área em estudo, à el evada toxicidade desta categoria e à disponibilidade de testes de screening rápido, prático e barato. Para se ter uma idéia da utilização desta classe de agrotóxicos, cerca de $90 \%$ dos indivíduos entrevistados relataram utilizar rotineiramente em seus trabalhos o inseticida organofosforado methamidophos, um inseticida caracteristicamente conhecido por sua neurotoxicidade.

A tabela 2 apresenta os resultados de média e desvio padrão da atividade destes indicadores biológicos de exposição.

Os valores médios obtidos no estudo de um grupo não-exposto foram utilizados para estabelecer um cut-off, ou seja, um valor significativo abaixo do qual os indivíduos seriam considerados possuidores de baixa atividade enzimática, característica esta observada nos casos de superexposição aos agrotóxicos anticolinesterásicos. Este ponto de corte foi estabelecido como sendo equivalente ao 50 percentil da distribuição dos val ores de atividade do grupo de referência. Para estabelecer o limite inferior, o cálculo utilizado foi equivalente a média - 1.645 s.d., correspondendo a 0.47 unidades internacionais (UI) para acetilcolinesterase e $2.32 \mathrm{UI} \mathrm{pa-}$ ra butirilcolinesterase. No conjunto de resultados estudados, onze indivíduos apresentavam atividade de acetilcolinesterase e doze indivíduos, a de butirilcolinesterase, baixas.

Em relação aos 101 trabalhadores rurais adultos, a tabela 2 apresenta dados relativos à análise estatística dos bancos de dados produzidos ao longo do projeto. Investigou-se, através de um teste de comparação (teste " $\mathrm{t}$ " para $a=0.05$ ), as médias do grupo potencial mente exposto, subdivido em duas categorias em função da presença ou ausência de sintomas. Foram analisadas as médias destas duas categorias nas diferentes variáveis epidemiológicas e também na listagem de sintomas apresentados pelos agricultores na entrevista médica. N ão foram encontradas diferenças significativas destes grupos em relação às atividades de produção e consumo, entretanto, a mesma análise em relação às variáveis da entrevista médica indica uma redução significativa entre os valores de acetilcolinesterase com os seguintes sintomas: dor de cabeça, cãi bras abdominais, ansiedade e insônia. 0 mesmo foi observado na atividade de butirilcolinesterase em relação à falta de ar.

Em relação ao exame físico propriamente dito e investigação clínica baseada em anamnese 
Tabela 2

Níveis de acetil e butirilcolinesterase encontrados em adultos e crianças moradores da região da M icrobacia do Córrego de São Lourenço

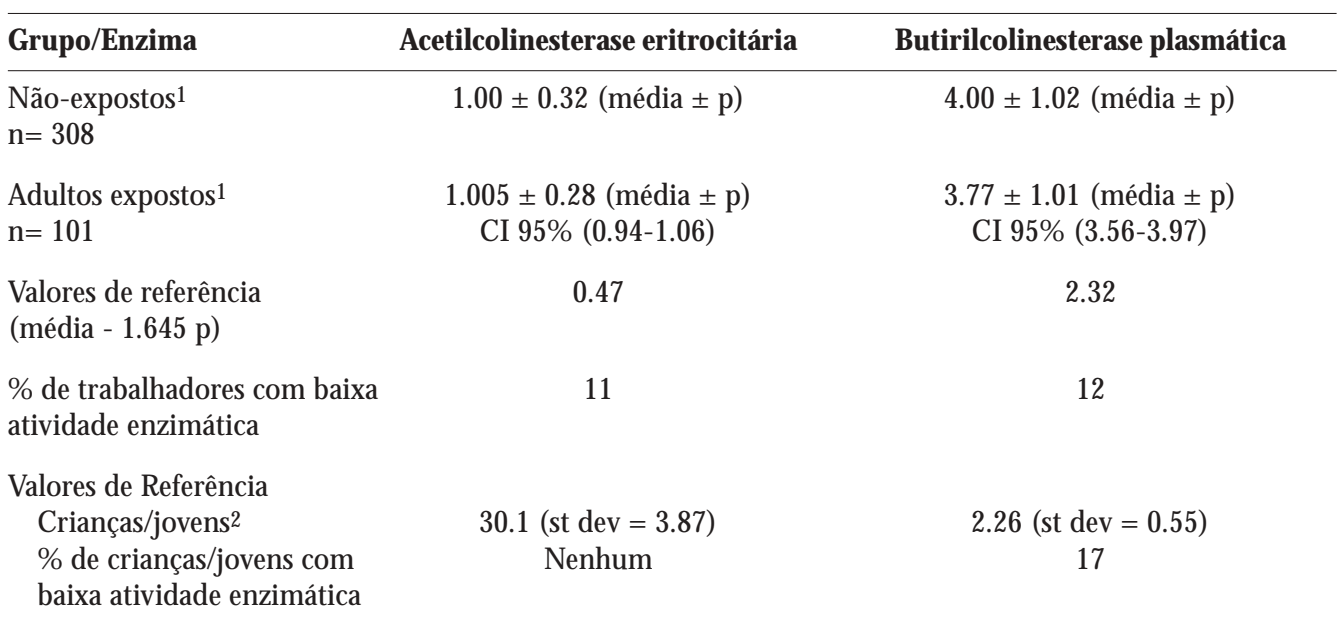

1 M étodo de dosagem: Ellman modificado por Cunha, J. C. (1996). Resultados expressos em unidades internacionais. 2 M étodo de dosagem: EQM Test Kit - EQM Research Inc, Cincinati - Ohio. Resultados expressos em unidades internacionais por $\mathrm{ml}$ de sangue total (atividade de colinesterase plasmática) ou por grama de hemoglobina (atividade de acetilcolinesterase eritrocitária). Valores normais são considerados equivalentes $a \geq 75 \%$ em relação aos valores obtidos em uma população de referência ( $n=40$ ) apresentados no estudo de validação descrito no manual do kit.

dirigida para sinais e sintomas de intoxicação por agrotóxicos, foi possível detectar 31 casos de intoxicação, sendo um de intoxicação aguda e trinta apresentando sinais e sintomas de intoxicação crônica. Este diagnóstico foi baseado principalmente nas observações do exame físico de alterações neurocomportamentais típicas desse tipo de intoxicação. Foi observado, na maioria desses casos, um quadro de polineuropatia periférica e alterações comportamentais que remetem a distúrbios ao nível do sistema nervoso central. Ainda em relação ao exame físico, fasciculação muscular foi observado como um distúrbio periférico recorrente em trinta indivíduos. É interessante observar que a análise estatística demonstrou que a média de atividade de acetilcolinesterase do grupo que apresentava fasciculação foi significativamente inferior em relação ao grupo que não apresentava este sinal. M odelos de regressão linear múltipla aplicados para investigar associações entre os indicadores biológicos e clínicos evidenciaram valores significativos para os sintomas de dor de cabeça e insônia e diminuição dos níveis de acetilcolinesterase. Quando as variáveis biológicas foram tratadas como variáveis categóricas ecolocadas em um modelo de regressão logística, foi possível observar associações significativas entre os níveis de acetilcolinesterase e os sintomas de insônia enervosismo (Odds ratio de 4.85 e 6.22, respectivamente).

$\mathrm{Na}$ análise dos resultados obtidos nos estudos com crianças trabal hadoras, com relação ao uso de agrotóxicos, foi observada situação idêntica àquela que já tínhamos constatado na investigação com a população adulta. M ais de trinta formulações diferentes foram mencionadas pelas crianças como de utilização rotineira. As mais utilizadas eram o paraquat, herbicida altamente tóxico; o mancozeb, fungicida de baixa toxicidade aguda; e o metamidophos, inseticida organofosforado altamente tóxico.

De acordo com a legislação brasileira específica (MT, 1997) etambém com o fabricante do kit utilizado, quando o resultado da atividade enzimática for menor que $75 \%$ do valor de referência, o exame deve ser repetido e, confirmando-se este valor, o indivíduo é considerado possivelmente contaminado. Segundo estes critérios, todas as crianças estudadas apresentaram valores normais de acetilcolinesterase, mas cerca de $17 \%$ das crianças avaliadas apresentaram níveis reduzidos de atividade da butirilcolinesterase, o que pode representar uma exposição recente, sem excluir a possibilidade de intoxicação, ou ainda uma distorção nos valores de re- 
ferência, visto que estes foram obtidos em outra população e para indivíduos adultos.

Finalmente, a última análise realizada foi a multivariada, através do emprego de regressão logística. Nesta análise os índices de colinesterases foram categorizados como normais e baixos e várias variáveis foram inseridas no modelo de regressão tendo os níveis de colinesterase como variável categórica constante. Os resultados que apresentaram associações significativas no modelo de regressão foram: sexo ( 0 dds ratio $=4,12 ; p<0,05)$ e atividade de aplicação de agrotóxico $(O R=5,80 ; p<0,05)$. Estes resultados são importantes, pois a partir deles pode-se inferir que, no grupo investigado, as crianças do sexo feminino teriam 4,12 vezes maior probabilidade de apresentar níveis reduzidos de colinesterases. Esta constatação éimportante, principalmente porque as crianças/jovens do sexo feminino ainda se encontram na fase da adolescência sem que se conheçam as conseqüências que esta exposição poderia trazer para a vida futura das mesmas e de suas famílias. Observa-se também que as crianças que trabal ham na lavoura na atividade de aplicação dos agrotóxicos têm 5.80 vezes maior expectativa de apresentarem níveis reduzidos de colinesterases. Certamente esta observação mostra, de maneira clara, a associação entre a atividade de aplicação e a diminuição da atividade enzimática, que pode, eventualmente, produzir danos à saúde.

\section{Considerações finais}

Uma série de fatores inter-relacionados contribui para a atual situação observada na região da M icrobacia do Córrego de São Lourenço, e a única maneira de entender e estimar a dimensão real do problema, bem como a influência de cada um de seus determinantes, é a utilização de uma abordagem integrada de avaliação.

Embora ainda muito limitados, os resultados já obtidos, mesmo que de forma compartimental izada, mostram claramente uma situação séria de contaminação humana e ambiental.

O bviamente, a continuidade/complementaridade destes estudos, com a introdução de novos parâmetros, como por exemplo, a contaminação humana e ambiental pelos demais agrotóxicos aí utilizados, os níveis da contaminação atmosférica e sua dispersão, a contaminação no interior das residências, o monitoramento sistemático da contaminação do rio São Lourenço por toda a gama de agrotóxicos bem como das águas subter râneas, a introdução de novos indicadores biológicos, entre outros, trará considerável contribuição para a montagem deste complexo quebra-cabeças que exige, antes de mais nada, o envolvimento de varias áreas do conhecimento.

Estudos envolvendo os possíveis problemas decorrentes da exposição continuada a esta gama de agrotóxicos, particularmente sobre as mulheres em idade fértil e as crianças, constituem necessi dade urgente e al guns já estão em andamento. Neste aspecto, encontram-se em fase de implementação, por este grupo, estudos envolvendo inicialmente a avaliação neuropsicológica e neurocomportamental de crianças com idades entre três a doze anos.

Os resultados disponíveis permitem afirmar que os principais fatores responsáveis pelos níveis de contaminação encontrados atualmente são a inexistência de uma política mais efetiva de fiscalização/controle/acompanhamento/ aconselhamento técnico adequado na utilização destes agentes; 0 baixo nível de escolaridade, que torna difícil o entendimento, mesmo superficial, de informações técnicas; as práticas exploratórias de propaganda das firmas produtoras; 0 desconhecimento de técnicas alternativas e eficientes de cultivo; a pouca atenção dada ao descarte de rejeitos e de embalagens; e a utilização dos agrotóxicos e exposição continuada a esses produtos.

Campanhas educativas que considerem o nível educacional e intelectual dos trabalhadores rurais necessitam ser realizadas. N este aspecto, o desenvolvimento de atividades específicas e periódicas, principalmente com as crianças, a serem realizadas nas escolas locais, certamente se constituirá num excelente modo para combater a situação encontrada a médio prazo.

Enquanto isso não for considerado uma prioridade de governo, a situação tende a se agravar e se expandir cada vez mais, ameaçando até mesmo os grandes centros urbanos próximos.

Todos os resultados demonstram claramente que a situação vigente é resultante da conjunção de vários fatores e que a intervenção unidirecional não resultará na solução para este problema. 


\section{Referências bibliográficas}

Agrofit (Base de dados de produtos agrotóxicos e fitossanitários) 1998. Secretaria de D efesa Agropecuária/ M inistério da Agricultura e do Abastecimento. Brasília.

Almeida WF \& Garcia EG 1991. Exposição dos trabalhadores rurais aos agrotóxicos no Brasil.

Revista Brasileira de Saúde 0 cupacional 19:7-11.

Alves SR 2000. Avaliação dos resíduos de agrotóxicos organofosforados e carbamatos por metodologia enzimática no Córrego de São Lourenço, N ova Friburgo-RJ, Brasil. Dissertação de mestrado. Escola Nacional de Saúde Pública, Fundação Oswaldo Cruz, Rio de Janeiro.

Bordenave JD 1988. 0 que é comunicação rural? Ed. Brasiliense, São Paulo.

Conama 1986. Resolução Conama n. 20, de 18 de junho de 1986.

Cunha-Bastos, VLF; Cunha-Bastos JF; Lima JS \& CastroFaria MV 1991. Brain acethylcholinesterase as an "in vitro" detector of organophosphorus and carbamate insecticides in the water. Water Research, 25(7):835840.

Cunha JC 1996. Otimização dos parâmetros práticos para a determinação da atividade de acetil e butirilcolinesterase. Dissertação de mestrado. Escola Nacional de Saúde Pública, Fundação Oswaldo Cruz, Rio de Janeiro.

Faria N M X, Facchini LA, Fassa AG \& Tomasi E 2000. Processo de produção rural e saúde na serra gaúcha: um estudo descritivo. Cadernos de Saúde Pública, 16(1): 115-128.

Gonzaga M C \& Santos SO 1992. Avaliação das condições de trabalho inerentes ao uso de agrotóxicos nos municípios de Fátima do Sul, Glória de Dourados e Vicentina - M ato Grosso do Sul, 1990. Revista Brasileira de Saúde 0 cupacional 20:42-46.

Green PE 1978. Analysing multivariate data. The Dryden Press, Illinois.

Kleinbaun DJ, Kupper LL \& Muller KE 1988. Applied re gression analysis and oher multivariate methods. @nd Ed., Boston \& PWS-Kent Pub. Co.

Lima JS et al. 1996. M ethyl parathion activation by partially purified rat brain fraction. Toxicological Letters, 87:53-60.
Merrit RW \& Cummins KW 1996. Introduction to the aquatic insects of N orth America. Kendall//Hunt Pub. Co., Iowa, USA.

M M A 1996. Os ecossistemas brasileiros e os principais macrovetores de desenvolvimento. M inistério do M eio Ambiente, dos Recursos Hídricos e da Amazônia Le gal, Secretaria de Coordenação dos Assuntos do M eio Ambiente, Programa Nacional do M eio Ambiente, Brasília.

MT 1997. Norma Regulamentadora n. 7, Segurança e Medicina do Trabalho. M inistério do Trabalho, 36 Ed. Atlas, São Paulo.

Neto JM N \& M oita GC 1998. Uma introdução à análise exploratória de dados multivariados. Química N ova, 21(4):467-469.

Oliveira-Silva J], M eyer A, M oreira, JC 2000. Cholinesterase activities determination in frozen blood samples: an improvement to the occupational monitoring in developing countries. Human and Environmental Toxicology 19:173-177.

Oliveira-Silva JJ, Alves SR, M eyer A, Sarcinelli PN, M attos RCO \& M oreira JC 2001. Influência de fatores socioeconômicos na contaminação por agrotóxicos, Brasil. Revista Saúde Pública 35(2):130-135.

Penteado JRW 1964. A técnica da comunicação humana. Livraria Pioneira Editora, São Paulo.

Peres F 1999. É veneno ou é remédio? Os desafios da comunicação rural sobre agrotóxicos. Dissertação de mestrado. Escola Nacional de Saúde Pública, Fundação Oswaldo Cruz, Rio de Janeiro.

Pimentel D 1996. Green revolution agriculture and chemical hazards. The Science of the Total Enviromment, 188(1):S86-S98.

Sindag 1999. Sindicato Nacional das Indústrias de D efensivos Agrícolas. Comunicação pessoal.

Sinitox 1998. Estatística anual de casos de intoxicação e envenenamento: Brasil: 1996. Centro de Informações Científica e Tecnológica, Fundação O swaldo Cruz, Rio de Janeiro.

Wiedermann PM 1993. Introduction risk perception and communication, Arbeiten Zur Risko Kommunikation. H eft 38 Jülich - April (mimeo).

Artigo apresentado em 10/10/2001

Versão final apresentada em 25/2/2002

Aprovado em 15/3/2002 